\title{
Study on Implementing Social Media With Teaching in Course of Technology and Innovation for Teachers for Undergraduates of the Faculty of Education, Naresuan University
}

\author{
Tipparat Sittiwong, Thanet Wongnam \\ Naresuan University, Phitsanulok, Thailand
}

\begin{abstract}
The objectives of this research were (1) to study on students' achievement after implementing social media with teaching in course of Technology and Innovation for Teachers; (2) to study on students' opinions on implementing social media with teaching in the course for undergraduates; and (3) to study on behavior of 38 students in Thai Language major, Faculty of Education, towards implementing social media with teaching in the course for undergraduates who attended the course in academic year 2014. The data was collected by using a learning achievement test before and after implementing social media in the course and a questionnaire for students concerning their opinions regarding implementing social media with the course. The data was analyzed by finding percentage, mean, standard deviation (SD), t-test dependent, and behavioral observation. The result showed that (1) the post-study achievement of 38 students was significantly higher than pre-study achievement with a statistical significance of .05; (2) the students "mostly agreed" on implementing social media with the course $(\mu=4.40$, $\sigma=.37$ ). After considering in each aspect, it was found that the three aspects that reached highest score respectively were overall image of implementing social media in classes $(\mu=4.74, \sigma=.45)$. Followed by those that reached the same score, which were, "implementing social media allowed students to exchange experience, knowledge, and attitudes between each other more" with ( $\mu=4.66, \sigma=.48)$, "implementing social media allowed students and teachers to exchange experience, knowledge, and attitudes with teachers more" with ( $\mu=4.66, \sigma=.48)$, "allowed students to work with each other or do more self-study" with ( $\mu=4.66, \sigma$ $=.48)$, "allowed students to study by themselves" with $(\mu=4.66, \sigma=.48)$, and "implementing social media in classes allowed students to submit assignment, and receive suggestions for improvement at all times" with ( $\mu=$ 4.66, $\sigma=.48$ ). The third was "implementing social media in classes allowed more methods for students to communicate with teachers" with ( $\mu=4.53, \sigma=.51$ ); and (3) behaviors of implementing social media with the course showed that (a) in terms of promoting knowledge, social media helped promoting knowledge between friends and between students and teachers in various concepts, which was the part that linked to practicing living together in society with others; (b) in terms of communication, students had a change to participate in more socialization by debating or asking questions via Facebook; (c) in terms of strengthening motivation, students were enthusiastic to learn and used the Facebook group for communication; (d) in terms of adjusting an opened-learning environment, this promoted the behavior that students would study and learn anywhere outside of classrooms,
\end{abstract}

Tipparat Sittiwong, assistant professor, Ed.D., Department of Educational Technology and Communication, Faculty of Education, Naresuan University.

Thanet Wongnam, master, Department of Physical Education and Exercise Science, Faculty of Education, Naresuan University. 
which helped learners to always learn not just in their classes; moreover, this would form the behavior of being able to work anywhere anytime, improve, and adjust their works by having records of the changes as well; and (e) in terms of supporting and promoting two-way communication, students were able to communicate and exchange information more than just in class and they were also encouraged to compete by producing portfolios and present them on Facebook and YouTube.

Keywords: social media, course of Technology and Innovations for Teachers

\section{Background of the Problem}

Social media are organized as social networks that are interesting and attractive to users because of their diversity. Many websites and social networks let users upload their photos as identification for other users to be acknowledged (Boyd \& Ellison, 2008). Social media are digital media, or software, which works web-based. When users see incidents, articles, experience, photos, videos, and music, they share with others online friends under their network, so that they know and gain benefits from that together quickly and efficiently. The advantages of implementing social media for education are (1) strengthening knowledge and intelligence; (2) forming communication, participation, and socialization; (3) strengthening motivation; (4) adjusting open-learning environment, easing connection, and building relations within classrooms; and (5) supporting two-way communication. This could also be adapted to managing course syllabus, e.g., collaborative learning, learning in small groups, or collaboratively forming knowledge. If teachers would like to apply the behaviors of using social media to be a part of the traditional style of study that the only source of information is teachers, then change it to the study environment where students can look for information from other sources by themselves and having teachers instruct the good and bad sources. Additionally, those websites can also be used as reference to the information found. They can also use networking websites as a mediator to communicate, exchange opinions, and show one's attitudes or knowledge. That would, as well, help eliminate the distance between teachers and students. The popular social media are, for example, Facebook and Myspace (Kabkham, 2012).

According to the advantages and benefits of social media mentioned and the research result of Tipparat Sittiwong (2014b) concerning student's opinions towards implementing Facebook in course of Design and Production of Graphic Media for Education for undergraduates, Technology and Communications major, Faculty of Education, Naresuan University, it was found that - student thought that other social networks, for example, Line, Skype, Twitter, YouTube, and Instagram, could also be implemented to classes. Therefore, the researchers were interested in studying results of implementing social media in the course in terms of knowledge and opinions of students. The result could, somehow, lead to engaging students to classes they attend and also for them to interact more with teachers. That would also promote the efficiency of classes and using technology creatively, and that is the benefit to the students, themselves.

\section{Objectives of Research}

(1) To study the achievement of students implementing social media in the course of Technology and Innovation for Teachers for undergraduates;

(2) To study students' opinions towards implementing social media in classes;

(3) To study students' behaviors concerning implementing social media in classes. 


\section{Scope of Research}

The sample consisted of 38 undergraduate students majoring in Thai Language, Faculty of Education, who attended a course on Technology and Innovations for Teachers, Academic Year 2014.

\section{Variables Used in the Research}

The independent variable was implementing social media with course of Technology and Innovations for Teachers.

Dependent variables were achievement, opinions, and behaviors of students who attended the course of Technology and Innovations for Teachers.

\section{Content Used in the Experiment}

Course 355211-Technology and Innovation for Teachers, 1st semester, Academic Year 2014.

\section{Tools Used in the Research}

In the research, we used the following tools:

(1) Teaching plan with the implementation of social media in the course;

(2) Achievement tests before and after the implementation of social media in the course;

(3) Questionnaire for students on students' opinions towards implementing social media in the course.

\section{How to Conduct the Tool Creating Process}

Researchers created the research tools using the following step:

Create the teaching plan with the implementation of social media in the course on Technology and Innovations for Teachers.

The teaching plan can be seen as an extension of the one previously used. Therefore, the researchers applied the principle of design and development of teaching, the "ADDIE Model" (Brahmawong, 2013), as the scope of creating the teaching plan. Details are given below. 


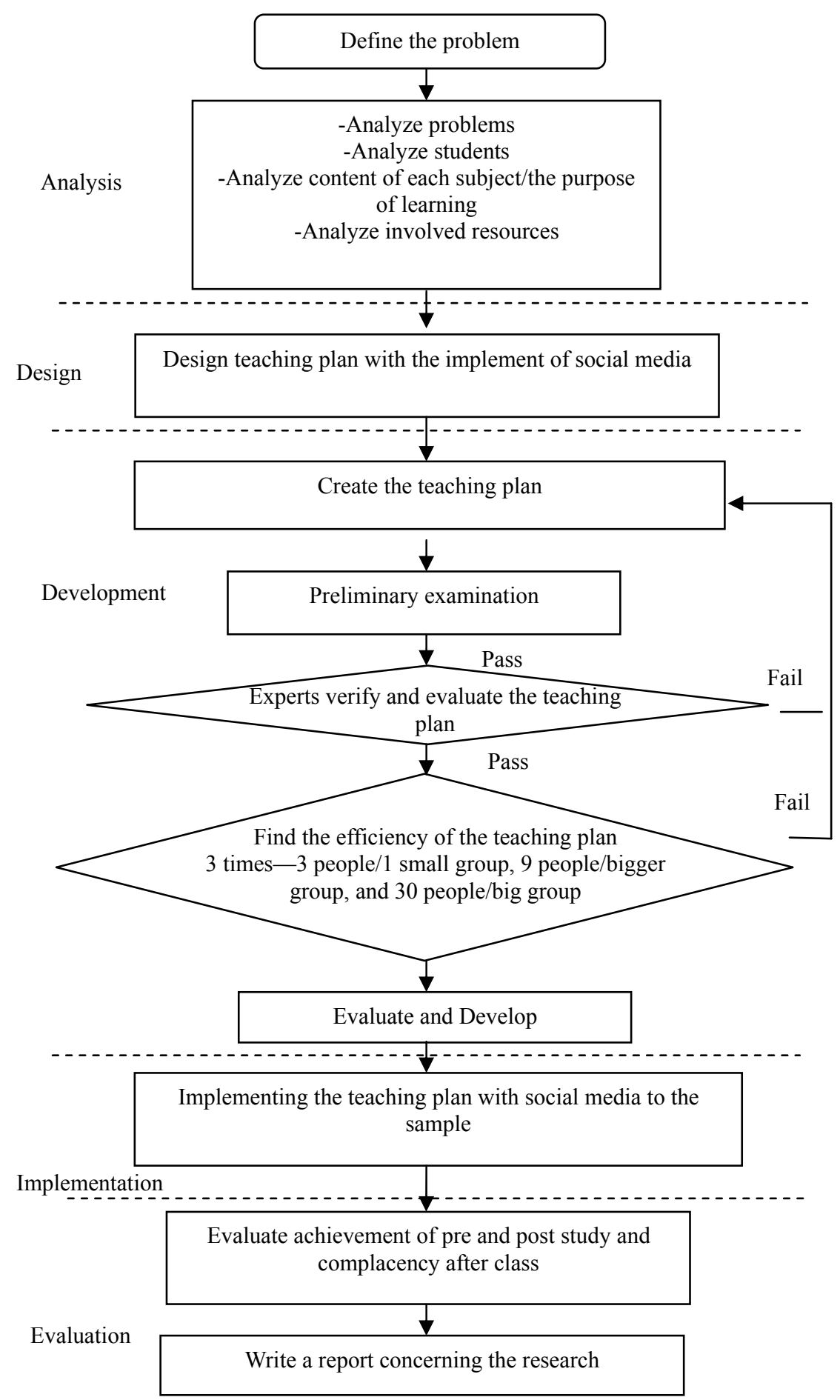

Figure 1. Structural learning plan with the implement of social media.

\section{Data Collection Methods of Demonstration}

The demonstration used group test by testing before and after the study (One Group Pre-test/Post-test design). 
Table 1

Methods of Individual Test and Group Test by Testing Before and After the Study

\begin{tabular}{lll}
\hline Pre-test & Treatment & Post-test \\
\hline $\mathrm{T}_{1}$ & $\mathrm{X}$ & $\mathrm{T}_{2}$
\end{tabular}

Notes. Meanings of signs: $\mathrm{X}$ means Treatment is the study that implements social media in course of Technology and Innovation for Teachers; $\mathrm{T}_{1}$ means Pretest; and $\mathrm{T}_{2}$ means Post-test.

Collected data of implementation the social media on course of Technology and Innovation for teachers by using the evaluating methods of achievement and opinions that the results:

(1) Pretested students by using achievement test. This was done before starting each subject in the syllabus;

(2) Treatment.

(a) Students study with the implementation of social media in the course;

(b) Teachers inform students of terms and regulations of studying with implementing social media in the course;

(c) Students study on all subjects in course syllabus, then do exercise according to each subject's purpose;

(d) Students take post-test by using achievement test;

(e) Teachers observe each student's behaviors and record in order to analyze each course's result. Then apply all the records to come up with final report after one semester;

(f) Teachers score students' answers;

(g) Teachers take the scores and statistically analyze them;

(h) Once all subjects are completed; students shall take questionnaire concerning implementing social media with course of Technology and Innovation for Teachers.

\section{Results and Discussion}

The results of implementing social media with course of Technology and Innovation for teachers show that the students reached significantly higher scores in post-test. The implemented social media was consistent with each subject and student, and students at this age were already familiar with social media in their daily life. They tended to look for information by searching social network more than by reading books. Moreover, learning from social media, somehow, helped students to master the achievement test, show decent thinking process, and invested more time in self-study.

The results from evaluating students' questionnaire, concerning the implemented social media in the course on Technology and Innovations for Teachers, show that students "highly" agree with the use of social media in the course ( $\mu=4.40, \sigma=.37)$. When considering each aspect, it was found that the three aspects with the highest scores were "overall image of implementing social media with the course" with $(\mu=4.74$, $\sigma=.45)$. Followed by the aspects that reached the same score, which were; "implementing social media with the course allowed students to exchange experience, knowledge, and attitudes between friends" with ( $\mu=$ 4.66, $\sigma=.48)$, "implementing social media with the course allowed students to exchange experience, knowledge, and attitudes between teachers and students" with $(\mu=4.66, \sigma=.48)$. Then "implementing social media with the course allowed students to work cooperatively or by themselves" with ( $\mu=4.66, \sigma$ $=.48)$, "implementing social media with the course allowed students to do self-study" with $(\mu=4.66, \sigma$ $=.48)$, "implementing social media with the course with learning allowed students to ask questions and 
improve their works at all time" with $(\mu=4.66, \sigma=.48)$. And the third was "implementing social media with the course helped students to communicate with teachers by more channels" with ( $\mu=4.53, \sigma=.51$ ). Students' opinions concerning implementing social media with the course was consistent with documents and researches that were related to implementing social media with learning both domestically and internationally. It was found that seven types of social media, for example, Facebook, Twitter, Blog, Google Docs, Wiki, DropBox, and YouTube, were implemented with seven types of learning, which were, cooperative learning, working together, thinking critically, distanced learning, integrated learning, working as a team, practicing reading and writing, scientifically learning, brainstorming, exchanging experience, teaching by having problems as a base, managing projects, and creating self-knowledge (Social Network, 2013).

The results of observing students' behaviors after implementing social media in the course on Technology and Innovations for Teachers revealed that social media helped improve students' knowledge. When students got to watch YouTube videos on several topics, students tended to communicate and exchange more information than in classes. It was because there was competition of presentation via Facebook and YouTube. The observed behavior was based on the benefit of implementing social media in classes, which helped the students gain knowledge, build a communication process, enforce participation including socialization. This also helped adjusting the learning environment which was easy to connect and build relationship in classrooms, and also support two-way communication. Additionally, it could be adapted to creating various types of learning, for example, cooperative learning, learning in small groups, or helping each other form knowledge. If teachers would like to apply those behaviors concerning implementing social media as a part of learning plan in order to make consistency with technology, they could adjust the traditional way of learning that "only had teachers as the central resource of knowledge" to the way that "students could look for information from other sources by themselves", by having teachers instructing the good and the bad ones. That would also allow them to check references. Moreover, using social network services as a mediate tool in order to exchange experience, show attitudes, and create one's own knowledge would help decreasing the distance between teachers and students as well (Kabkham, 2012).

\section{Suggestions}

\section{Suggestions From the Research}

More types of social media should be implemented for a variety of studies.

Other types of social media should be implemented in other classes for the opportunity of students to exchange knowledge and improve communication skills in order to allow to do self-study.

The results of implementing social media with classes should be analyzed and adapted to other classes as well.

\section{Suggestions for Further Research}

(1) Other style of teaching should be implemented with social media;

(2) Other types of social media should be studied on in order to support their study.

\section{Conclusion}

The post-study achievement of 38 students was significantly higher than pre-study achievement; the students "mostly agreed" on implementing social media with the course. After considering in each aspect, it was found that the three aspects that reached highest score respectively were overall image of implementing 
social media in classes and behaviors of implementing social media with the course showed that (1) in terms of promoting knowledge, social media helped promoting knowledge between friends and between students and teachers in various concepts, which was the part that linked to practicing living together in society with others; (2) in terms of communication, students had a change to participate in more socialization by debating or asking questions via Facebook; (3) in terms of strengthening motivation, students were enthusiastic to learn and used the Facebook group for communication; (4) in terms of adjusting an opened-learning environment, this promoted the behavior that students would study and learn anywhere outside of classrooms, which helped learners to always learn not just in their classes; moreover, this would form the behavior of being able to work anywhere anytime, improve, and adjust their works by having records of the changes as well; and (5) in terms of supporting and promoting two-way communication, students were able to communicate and exchange information more than just in class and they were also encouraged to compete by producing portfolios and present them on Facebook and YouTube.

\section{References}

Boyd, D. M., \& Ellison, N. B. (2008). Social network sites: Definition, history, and scholarship. Journal of Computer-Mediated Communication, 13, 210-230.

Brahmawong, C. (2013). Developmental testing of media and instructional package. Retrieved September 17, 2016 from http://www.educ.su.ac.th/2013/images/stories/081957-02.pdf

Kabkham, T. (2012). What is social media? Retrieved July 17, 2013 from $\mathrm{http} / /$ krunum.wordpress.com/2010/06/02/social-network

Sittiwong, T. (2014a). Result of implementing QSCCS along with Facebook to support self-studying in 21st century in Printing and Advertising Technology course for Technology and Communications undergraduates (Research Report), Naresuan University, Phitsanulok.

Sittiwong, T. (2014b). Study on students' opinions towards implementing Facebook with course of Design and Graphic Production for Education, for undergraduates, Technology and Communications, Faculty of Education, Naresuan University (Research Report), Naresuan University, Phitsanulok.

Social Network. (2016). Retrieved September 17, 2016 from https://sites.google.com/site/233socialnetwork/ 